\title{
Individualized induction chemotherapy by pre-treatment plasma Epstein-Barr viral DNA in advanced nasopharyngeal carcinoma
}

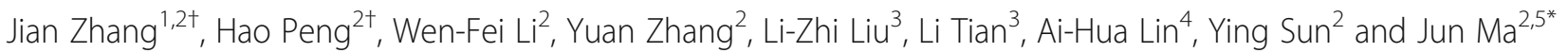

\begin{abstract}
Background: The role of pretreatment Epstein-Barr virus DNA (pre-DNA) for individualized induction chemotherapy (IC) in locoregionally advanced nasopharyngeal carcinoma (LA-NPC) still remains unknown. We aimed to address this clinical issue.

Methods: In total, data on 6218 patient with newly diagnosed LA-NPC receiving concurrent chemoradiotherapy (CCRT) with or without IC were retrospectively reviewed. Receiver operating characteristics (ROC) curve was adopted to calculate the cut-off value of pre-DNA based on disease-free survival (DFS). Propensity score matching (PSM) method was adopted to balance prognostic factors and match patients. Survival outcomes between IC + CCRT and CCRT groups were compared.

Results: Among the original cohort, no survival difference between IC + CCRT and CCRT groups was found. The cut-off value of pre-DNA was 4650 copies/ml (area under curve [AUC], 0.620; sensitivity, 0.6224; specificity, 0.5673). For patients with Pre-DNA $\leq 4650$ copies $/ \mathrm{ml}$, the IC + CCRT and CCRT groups also achieved comparable survival outcomes $(P>0.05$ for all rates). However, IC + CCRT was associated with significantly improved 3-year DFS (78.6\% vs. 74.8\%, $P=0$. 03), overall survival (OS; $91.4 \%$ vs. $87.5 \%, P=0.002$ ) and distant metastasis-free survival (DMFS; $86.0 \%$ vs. $82.2 \%$, $P=0.036)$ for patient with pre-DNA $>4650$ copies $/ \mathrm{ml}$. Multivariate analysis also confirm that IC + CCRT was an independent prognostic factor for DFS (HR, $0.817 ; 95 \% \mathrm{Cl}, 0.683-0.977 ; P=0.027)$, OS $(\mathrm{HR}, 0.675 ; 95 \% \mathrm{Cl}, 0$. $537-0.848 ; P=0.001)$ and DMFS (HR, 0.782; $95 \% \mathrm{Cl}, 0.626-0.976 ; P=0.03)$.
\end{abstract}

Conclusions: Pre-DNA may be a feasible and powerful consideration for individualized IC apart from other baseline clinical characteristics in LA-NPC.

Keywords: Nasopharyngeal carcinoma, Locoregionally advanced, Induction chemotherapy, Epstein-Barr virus DNA, Prognosis

\footnotetext{
* Correspondence: majun2@mail.sysu.edu.cn

${ }^{\dagger}$ Jian Zhang and Hao Peng contributed equally to this work.

2Department of Radiation Oncology, Sun Yat-sen University Cancer Center, State Key Laboratory of Oncology in Southern China, Collaborative

Innovation Center for Cancer Medicine, Guangdong Key Laboratory of Nasopharyngeal Carcinoma Diagnosis and Therapy, Guangzhou 510060, People's Republic of China

${ }^{5}$ State Key Laboratory of Oncology in South China, Department of Radiation Oncology, Sun Yat-sen University Cancer Center, 651 Dongfeng Road East, Guangzhou 510060, People's Republic of China

Full list of author information is available at the end of the article
}

\section{Background}

Nasopharyngeal carcinoma (NPC) is a malignancy arising from nasopharynx epithelia, and epidemic in Southeast and Eastern Asia. The highest incidence occurred in Southeast China and is approximately $20-50$ per 100,000 people $[1,2]$. Radiation therapy (RT) is the primary and only curative treatment for non-disseminated disease as a result of its complicate anatomy location and sensitivity to irradiation. Concurrent chemoradiotherapy (CCRT) is now the main treatment for locoregionally advanced NPC (LA-NPC) [3, 4]. However,

(c) The Author(s). 2018 Open Access This article is distributed under the terms of the Creative Commons Attribution 4.0 International License (http://creativecommons.org/licenses/by/4.0/) which permits unrestricted use, distribution, and reproduction in any medium, provided you give appropriate credit to the original author(s) and the source, provide a link to the Creative Commons license, and indicate if changes were made. The Creative Commons Public Domain Dedication waiver (http://creativecommons.org/publicdomain/zero/1.0/) applies to the data made available in this article, unless otherwise stated. 
prognosis of LA-NPC after radical radiotherapy still remains poor [5] and distant metastasis is the main failure pattern [6]. To further decrease risks of distant metastasis and improve clinical outcomes, induction chemotherapy (IC) additional to CCRT has been proven a feasible and effective strategy [7-9]. Notably, there is increasing data showing that IC additional to CCRT could not bring therapeutic gain to patients with $\mathrm{T} 3-4 \mathrm{~N} 0-1$ disease $[10,11]$, indicating that some patients with low risk did not need IC. However, current risk stratification and treatment delivery mainly refer to TNM staging system which may be insufficient to identify the low-risk patients [12]. Therefore, it is urgently needed to identify powerful factors to help risk stratification and treatment strategy selection.

Plasma Epstein-Barr virus (EBV) DNA has been proven an important factor in risk stratification and prognosis prediction in NPC [13-15]. Moreover, plasma EBV DNA could also play an important role in decision making. For example, post-treatment EBV DNA could act as an indicator for individualized adjuvant chemotherapy [16]. Recently, Guo et al. [17] and Peng et al. [18] found that pre-treatment Epstein-Barr virus (pre-DNA) could guide the selection of IC in LA-NPC. However, the sample size in these two studies was small. Moreover, the treatment modality was also not uniform since many patients did not received concurrent chemotherapy, which would subject the study to treatment-related bias. Therefore, it is necessary to further address this question and provide robust evidence.

Based on this premise, we conducted this retrospective study using a big-data, intelligence database platform to identify and evaluate the value of pre-DNA for risk stratification and treatment selection in LA-NPC.

\section{Methods}

\section{Patient selection}

In this study, we reviewed and identified patients with newly diagnosed stage I-IVA NPC who were treated between November 2009 and February 2015 using the big-data, intelligence platform at Sun Yat-sen University Cancer Center [19]. Patients meeting the following criteria were included for this study: (1) newly diagnosed stage III-IVA NPC; (2) data on pre-DNA was available; (3) receiving intensity-modulated radiotherapy (IMRT); (4) age 18 years or older; (5) receiving CCRT with or without IC; (6) the cycles of IC should be $\geq 2$. Finally, 6218 patients were recruited for the current study. This study was approved by the Research Ethics Committee of our center. Informed consent was obtained from all the patients. Study data was deposited at the Research Data Deposit platform (http://www.researchdata.org.cn/, RDDA2018000545).

\section{Clinical staging}

Before treatment, patients received physical examination first. Then imaging methods were performed including magnetic resonance imaging (MRI) of the neck and nasopharynx, whole-body bone scan, abdominal sonography or computed tomograph, chest radiography or tomograph. Positron emission tomography (PET)-CT would also be recommended if clinically indicated. Imaging data were reviewed by two radiologists (L-ZL and LT) independently to stage all patients based on the 8th edition of the International Union against Cancer/ American Joint Committee on Cancer (UICC/AJCC) staging system manual.

\section{Real-time quantitative EBV DNA PCR}

Pre-DNA concentration was detected using real-time quantitative polymerase chain reaction (RT-PCR) which was described previously [20]. The RT-PCR system was developed and targeted the BamHI-W region of the EBV genome using primers 5'-GCCAGAGGTAAGTGGAC TTT-3' and 5'-TACCACCTCCTCTTCTTGCT-3'. The dual fluorescence-labeled oligomer 5'-(FAM) CACA CCCAGGCACACACTACACAT (TAMRA)-3' served as a probe. Sequence data for the EBV genome were obtained from the GeneBank sequence database.

\section{Clinical treatment}

All patients underwent radical IMRT. The prescribed radiation doses were $66 \mathrm{~Gy}$ or greater to the primary tumor and 60-70 Gy to the involved neck area. All potential sites of local infiltration and bilateral cervical lymphatics were irradiated to $50 \mathrm{~Gy}$ or greater. All patients were treated with $30-35$ fractions with five daily fractions per week for 6-7 weeks.

Since our study is retrospective and patients were treated before 2016 when the role of IC has not been well established. Therefore, the selection of IC and corresponding regimens mainly depended on clinicians' experience and decisions because there was no consensus in our center. IC regimens consist of platinum-based agents including 5-fluorouracil with cisplatin (PF), docetaxel with cisplatin (TP) and triple of docetaxel with 5-fluorouracil and cisplatin (TPF). Concurrent chemotherapy consisted of weekly $\left(30-40 \mathrm{mg} / \mathrm{m}^{2} \mathrm{~d} 1\right)$ or tri-weekly $\left(80-100 \mathrm{mg} / \mathrm{m}^{2} \mathrm{~d} 1\right)$ cisplatin.

\section{Follow-up strategy}

Patients were followed by imaging methods every 3 months during first 2 years, 6 months during 3-5th year and annually thereafter. Follow-up duration was measured from first day of pathological diagnosis to last visit or death. The first endpoint is disease-free survival (DFS, defined as the time to first event or death from any cause). Other endpoints include overall survival (OS, 
time to death from any cause), distant metastasis-free survival (DMFS, time to first distant failure) and locoregional relapse-free survival (LRRFS, time to first local or regional recurrence or both).

\section{Statistical method}

Propensity score matching (PSM) using logistic regression were adopted to balance factors and match patients. The Chi-square test or Fisher's exact test were used to compare categorical variables and non-parametric test for continuous variables. Receiver operation characteristic (ROC) curve was applied to calculate the cut-off value of pre-DNA for DFS. Life-table estimation was performed using the Kaplan-Meier method and survival difference was compared by log-rank test. The multivariate Cox proportional hazards model was used to estimate hazard ratios (HRs) and 95\% confidence intervals (CIs) with following factors; gender, age, smoking, drinking, family history of cancer, lactate dehydrogenase (LDH), T category, $\mathrm{N}$ category, overall stage, and treatment arms (IC + CCRT vs. CCRT). All tests were two-sided; $P<0.05$ was considered significant. Statistical Package 12 (StataCorp LP, College Station, TX, USA) was used for all analyses.

\section{Results}

\section{Baseline characteristics}

In total, 6218 patients with LA-NPC were included in this study and baseline characteristics were summarized in Additional file 1: Table S1. The whole cohort carried a male-to-female ratio of 2.86 , and the median age was 45 (range, 18-79) yeas-old. The median follow-up duration was 43.0 (range, 0.3-103.6) months. Overall, 3510 (56.4\%) patients received IC + CCRT and 2708 (43.6\%) received CCRT alone. Specifically, 1460 (41.6\%), 977 (27.8\%) and $1073(30.6 \%)$ patients received induction TPF, PF and TP regimens, respectively. Obviously, the IC + CCRT group had a higher percentage of T4, N3 and stage IV disease $(P<0.001)$. Besides, host and tumor-related factors were also not balanced between these two groups $(P<0.05)$.

\section{Survival analysis within whole cohort}

First, we compared the survival outcomes of IC+ CCRT with that of CCRT among the original cohort. In total, 2241 pairs were selected by PSM from the 6218 patients (Table 1), and factors were well balanced between the two groups. The 3-year DFS (82.5\% vs. $81.7 \%, P=0.473)$, OS $(92.3 \%$ vs. $91.6 \%, P=$ $0.263)$, DMFS $(89.1 \%$ vs. $88.2 \%, P=0.339)$ and LRRFS (92.0\% vs. $93.1 \%, P=0.288)$ (Fig. 1 ) rates were comparable between IC + CCRT and CCRT groups. When multivariate analysis performed, results were consisted
Table 1 Baseline characteristics of selected 2241 pairs with locoregionally advanced nasopharyngeal carcinoma

\begin{tabular}{|c|c|c|c|}
\hline \multirow[t]{2}{*}{ Characteristics } & $\begin{array}{l}\text { CCRT } \\
(n=2241)\end{array}$ & $\begin{array}{l}\text { IC + CCRT } \\
(n=2241)\end{array}$ & \multirow[t]{2}{*}{$P$ value } \\
\hline & №. (\%) & No. (\%) & \\
\hline Gender & & & $0.838^{a}$ \\
\hline Male & $585(26.1)$ & $579(25.8)$ & \\
\hline Female & $1656(73.9)$ & $1662(74.2)$ & \\
\hline Age (years) & & & $0.791^{b}$ \\
\hline Median (range) & $44(18-77)$ & $45(18-76)$ & \\
\hline Smoking & & & $0.828^{a}$ \\
\hline Yes & $819(36.5)$ & $812(36.2)$ & \\
\hline No & $1422(63.5)$ & 1429 (63.8) & \\
\hline Drinking & & & $0.703^{\mathrm{a}}$ \\
\hline Yes & $321(14.3)$ & $330(14.7)$ & \\
\hline No & $1920(85.7)$ & 1911 (85.3) & \\
\hline $\begin{array}{l}\text { Family History } \\
\text { of cancer }\end{array}$ & & & $0.606^{\mathrm{a}}$ \\
\hline Yes & $572(25.5)$ & $557(24.9)$ & \\
\hline No & $1669(74.5)$ & $1684(75.1)$ & \\
\hline$T_{\text {category }}{ }^{c}$ & & & $0.208^{a}$ \\
\hline $\mathrm{T} 1$ & $107(4.8)$ & $136(6.0)$ & \\
\hline $\mathrm{T} 2$ & $179(8.0)$ & $176(7.9)$ & \\
\hline T3 & $1461(65.2)$ & $1416(63.2)$ & \\
\hline T4 & $494(22.0)$ & $513(22.9)$ & \\
\hline$N$ category $^{c}$ & & & $0.03^{\mathrm{a}}$ \\
\hline No & $186(8.3)$ & $188(8.4)$ & \\
\hline N1 & $1151(51.4)$ & $1138(50.8)$ & \\
\hline N2 & $635(28.3)$ & $699(31.2)$ & \\
\hline N3 & $269(12.0)$ & $216(9.6)$ & \\
\hline Overall stage ${ }^{c}$ & & & $0.501^{a}$ \\
\hline III & $1516(67.6)$ & 1537 (68.6) & \\
\hline IVA-B & $725(32.4)$ & $704(31.4)$ & \\
\hline LDH (U/L) & & & $0.204^{b}$ \\
\hline $\begin{array}{l}\text { Median } \\
\text { (range) }\end{array}$ & $174(67-1009)$ & $176(39-753)$ & \\
\hline $\begin{array}{l}\text { EBV-DNA } \\
\text { (copies/ml) }\end{array}$ & & & $0.141^{b}$ \\
\hline $\begin{array}{l}\text { Median } \\
\text { (range) }\end{array}$ & $6345(0-13,100,000)$ & $4610(0-9,080,000)$ & \\
\hline
\end{tabular}

Abbreviations: NPC nasopharyngeal carcinoma, CCRT concurrent chemoradiotherapy, $I C$ induction chemotherapy, $L D H$ lactate dehydrogenase, $E B V$-DNA Epstein-Barr virus DNA

${ }^{a} P$ values were calculated by $C$ Chi-square test

${ }^{\mathrm{b}} P$ values were calculated by $t$ test

${ }^{C}$ According to the 8 th edition of UICC/AJCC staging system

with that of univariate analysis and treatment arm $(\mathrm{IC}+$ CCRT vs. CCRT) was not an independent prognostic factor for DFS, OS, DMFS and LRRFS (Table 2). 


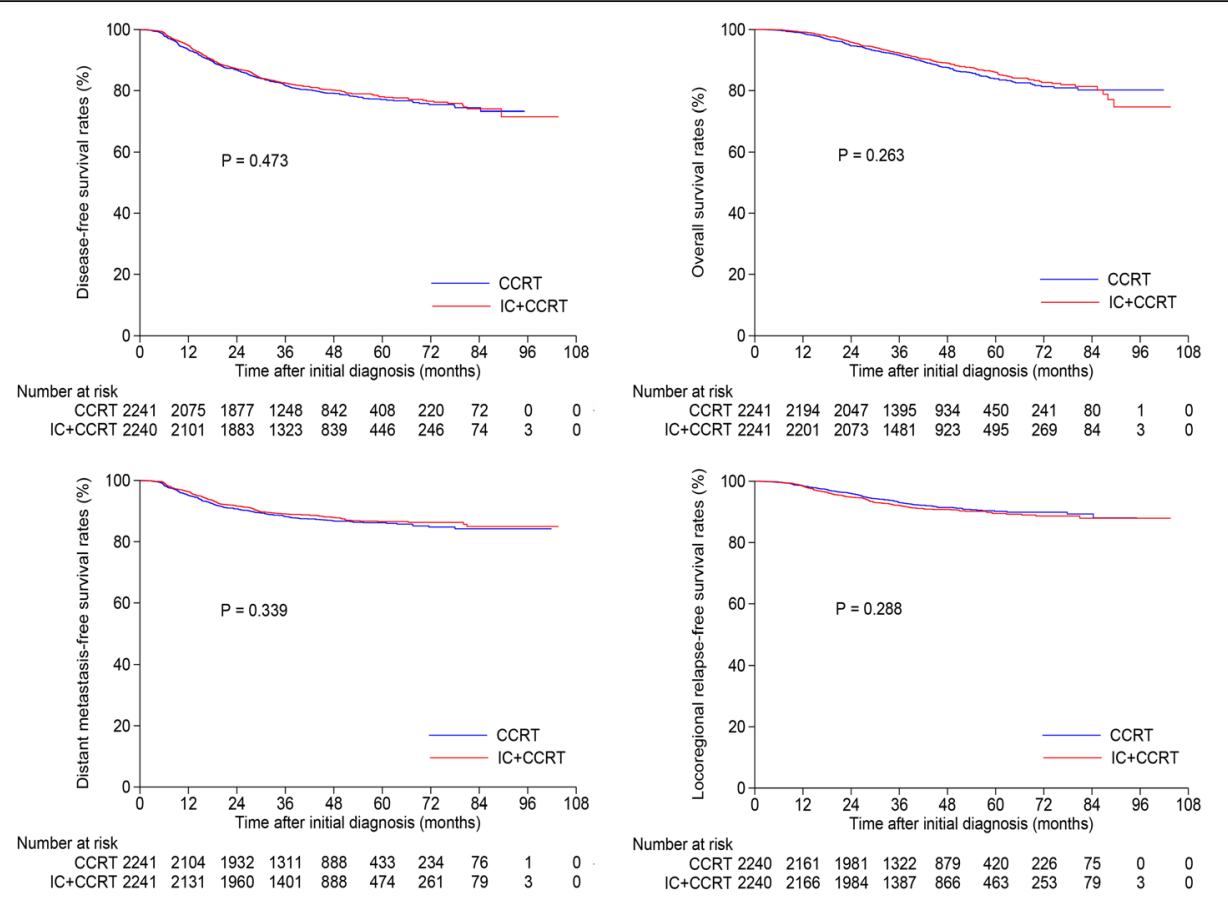

Fig. 1 Kaplan-Meier disease-free survival, overall survival, distant metastasis-free survival and locoregional relapse-free survival curves for the selected 2241 pairs with stage III-IVA nasopharyngeal carcinoma receiving concurrent chemoradiotherapy with or without induction chemotherapy

\section{Cut-off value of pre-DNA}

The median pre-DNA concentration for the $6218 \mathrm{pa}$ tients was 3740 (range, 0-68,700,000) copies $/ \mathrm{ml}$. Based on ROC analysis, the cut-off value of pre-DNA is 4650 copies $/ \mathrm{ml}$ (sensitivity $=0.6224$, specificity $=0.5673$, area under curve $[\mathrm{AUC}]=0.620$ ) for DFS (Fig. 2), 4315 (sensitivity: 0.667; specificity: 0.545; AUC $=0.634$ ) for OS, 4315 (sensitivity: 0.674; specificity: 0.547; $\mathrm{AUC}=0.649$ ) for DMFS and 2055 (sensitivity: $0.680 ;$ specificity: 0.446; $\mathrm{AUC}=0.568$ ). Then, 4650 copies $/ \mathrm{ml}$ was used as the threshold. We further evaluated whether this cut-off value could subdivide patients into different risk groups. Undoubtedly, patients with pre-DNA $>4650$ copies $/ \mathrm{ml}$ achieved significantly poorer survival compared with those with pre-DNA $\leq 4650$ copies $/ \mathrm{ml}$ in both stage III (Additional file 2: Figure S1) and stage IV (Additional file 3: Figure S2) subgroups. Therefore, this cut-off value is valid, and patients with pre-DNA $\leq$ 4650 copies $/ \mathrm{ml}$ were classified as low-DNA group and those with pre-DNA $>4650$ copies $/ \mathrm{ml}$ as highDNA group.

\section{Survival outcomes within low-DNA group}

We further evaluated the survival difference between the IC + CCRT and CCRT groups among patients with lowDNA. In total, 3292 patients had a pre-DNA $\leq 4650$ copies/ml (Additional file 4: Table S2). After matching, 1191 pairs were selected and baseline information was presented in Additional file 5: Table S3. The 3-year DFS, OS, DMFS and LRRFS rates for IC + CCRT vs. CCRT were $88.2 \%$ vs. $86.2 \%(P=0.315), 95.0 \%$ vs. $94.7 \%$ ( $P$ $=0.979), 93.0 \%$ vs. $92.5 \%(P=0.859)$ and $93.8 \%$ vs. 93.9\% ( $P=0.743 ;$ Fig. 3$)$, respectively. Multivariate analysis also found that there was no significantly survival difference between IC + CCRT and CCRT groups $(P>0.05$ for all rates, Additional file 6: Table S4). Therefore, IC + CCRT and CCRT achieved similar outcomes in low-DNA group.

\section{Survival outcomes within high-DNA group}

Among the 2926 patients with pre-DNA $>4650$ copies/ $\mathrm{ml}$ (Additional file 7: Table S5), 945 pairs were selected by PSM and baseline characteristics were presented in Additional file 8: Table S6. The 3-year DFS, OS, DMFS and LRRFS rates for IC + CCRT vs. CCRT were $78.6 \%$ vs. $74.8 \%(P=0.03), 91.4 \%$ vs. $87.5 \%(P=0.002), 86.0 \%$ vs. $82.2 \%$ vs. $(P=0.036)$ and $90.4 \%$ vs. $91.4 \%(P=0.691$; Fig. 4), respectively. When entered into multivariate analysis, treatment (IC + CCRT vs. CCRT) was identified as an independent prognostic factor for DFS (HR, 0.817; 95\% CI, 0.683-0.977; $P=0.027$ ), OS (HR, 0.675; 95\% CI, $0.537-0.848 ; P=0.001)$ and DMFS (HR, 0.782; 95\% CI, 0.626-0.976; $P=0.03$; Table 3). Thus, IC + CCRT was superior to CCRT among patients with high-DNA. 
Table 2 Results of multivariate analysis for the selected 2241 pairs

\begin{tabular}{|c|c|c|c|}
\hline Endpoints & Variable & $\mathrm{HR}(95 \% \mathrm{Cl})$ & $P$ value $^{a}$ \\
\hline \multirow[t]{7}{*}{$\overline{D F S}$} & Gender, female vs. male & $0.799(0.681-0.937)$ & 0.006 \\
\hline & Age, $>44$ vs. $\leq 44 y$ & $1.191(1.041-1.362)$ & 0.011 \\
\hline & $\mathrm{LDH}_{;}>245$ vs. $\leq 245 \mathrm{U} / \mathrm{L}$ & $1.596(1.298-1.962)$ & $<0.001$ \\
\hline & T category; T3-4 vs. T1-2 & $1.283(1.043-1.578)$ & 0.018 \\
\hline & N category, N2-3 vs. N0-1 & $1.742(1.506-2.015)$ & $<0.001$ \\
\hline & Overall stage, IVA vs. III & $1.867(1.632-2.136)$ & $<0.001$ \\
\hline & Treatment, IC + CCRT vs. CCRT & $0.955(0.837-1.090)$ & 0.494 \\
\hline \multirow[t]{6}{*}{ OS } & Gender; female vs. male & $0.700(0.562-0.871)$ & 0.001 \\
\hline & Age, $>44$ vs. $\leq 44 y$ & 1.479 (1.238-1.768) & $<0.001$ \\
\hline & $\mathrm{LDH}_{;}>245$ vs. $\leq 245 \mathrm{U} / \mathrm{L}$ & $1.734(1.343-2.238)$ & $<0.001$ \\
\hline & N category, N2-3 vs. N0-1 & $1.922(1.589-2.323)$ & $<0.001$ \\
\hline & Overall stage, IVA vs. III & $2.140(1.795-2.550)$ & $<0.001$ \\
\hline & Treatment, IC + CCRT vs. CCRT & $0.894(0.752-1.063)$ & 0.207 \\
\hline \multirow[t]{5}{*}{ DMFS } & Gender; female vs. male & $0.758(0.616-0.932)$ & 0.009 \\
\hline & $\mathrm{LDH}_{;}>245$ vs. $\leq 245 \mathrm{U} / \mathrm{L}$ & $1.938(1.519-2.473)$ & $<0.001$ \\
\hline & N category, N2-3 vs. N0-1 & 1.959 (1.649-2.327) & $<0.001$ \\
\hline & Overall stage, IVA vs. III & $1.989(1.678-2.357)$ & $<0.001$ \\
\hline & Treatment, IC + CCRT vs. CCRT & $0.926(0.782-1.096)$ & 0.369 \\
\hline \multirow[t]{6}{*}{ LRRFS } & Smoking, yes vs. no & $1.263(1.024-1.557)$ & 0.029 \\
\hline & Age, $>44$ vs. $\leq 44 \mathrm{y}$ & $1.345(1.088-1.662)$ & 0.006 \\
\hline & T category, T3-4 vs. T1-2 & $1.494(1.062-2.103)$ & 0.021 \\
\hline & N category; N3 vs. N2 & $1.624(1.297-2.033)$ & $<0.001$ \\
\hline & Overall stage, IVA vs. III & 1.654 (1.341-2.039) & $<0.001$ \\
\hline & Treatment, IC + CCRT vs. CCRT & $1.114(0.906-1.369)$ & 0.306 \\
\hline
\end{tabular}

Abbreviations: DFS disease-free survival, OS overall survival, DMFS distant metastasis-free survival, LRRFS locoregional relapse-free survival, $H R$ hazard ratio, $C I$ confidence interval, IC induction chemotherapy, CCRT concurrent chemoradiotherapy, LDH lactate dehydrogenase

${ }^{a} P$-values were calculated using an adjusted Cox proportional hazards model with backward elimination and the following variables were included: gender (female vs. male), age (> 44y vs. $\leq 44 \mathrm{y}$ ), smoking (yes vs. no), drinking (yes vs. no), family history of cancer (yes vs. no), LDH (> 245 vs. $\leq 245 \mathrm{U} / \mathrm{L}$ ), $\mathrm{T}$ category (T3-4 vs. T1-2), N category (N2-3 vs. N0-1), overall stage (IVA vs. III) and treatment (IC + CCRT vs. CCRT)

\section{Discussion}

Our current study presented that patients with LA-NPC and low pre-DNA $(\leq 4650$ copies $/ \mathrm{ml})$ could not benefit from additional IC to CCRT while patients with high pre-DNA (>4650 copies $/ \mathrm{ml})$ could, indicating that pre-DNA could act as an effective and powerful indicator for the delivery of IC in LA-NPC. Notably, to avoid extended follow-up and identify a cut-off value for earlier individualized treatment, we therefore calculated the cut-off value of pre-DNA based on DFS because it was a feasible surrogate endpoint for OS [21, 22]. To the best of our knowledge, this is the largest cohort study in evaluating the role of pre-DNA for treatment strategies selection.

In the era of IMRT, distant metastasis has emerged as the predominant treatment failure pattern, especially for advanced disease [23, 24]. Additional cycles of chemotherapy to CCRT are needed to reduce distant metastasis and further improve survival. Adjuvant chemotherapy (AC) was firstly considered as it was proven effective by Intergroup 0099 study [3]. However, subsequent studies found that $\mathrm{AC}$ additional to CCRT may be useless $[25,26]$. Furthermore, the severe toxicities of AC constrain its wide usage. Given these concerns, other chemotherapy strategies with better efficacy and compliance should be identified. IC, delivered before radiotherapy, has caught a lot of attention for its better compliance and early eradication of subclinical micro-metastasis. However, results from previous clinical trials comparing IC + CCRT with CCRT were controversial as the three achieved positive outcomes $[8,27,28]$ while the study by Tan et al. [29] achieved negative results, indicating that not all the patients with LA-NPC could benefit from IC. Moreover, retrospective evidence showed that IC could not produce therapeutic gain for patients with 


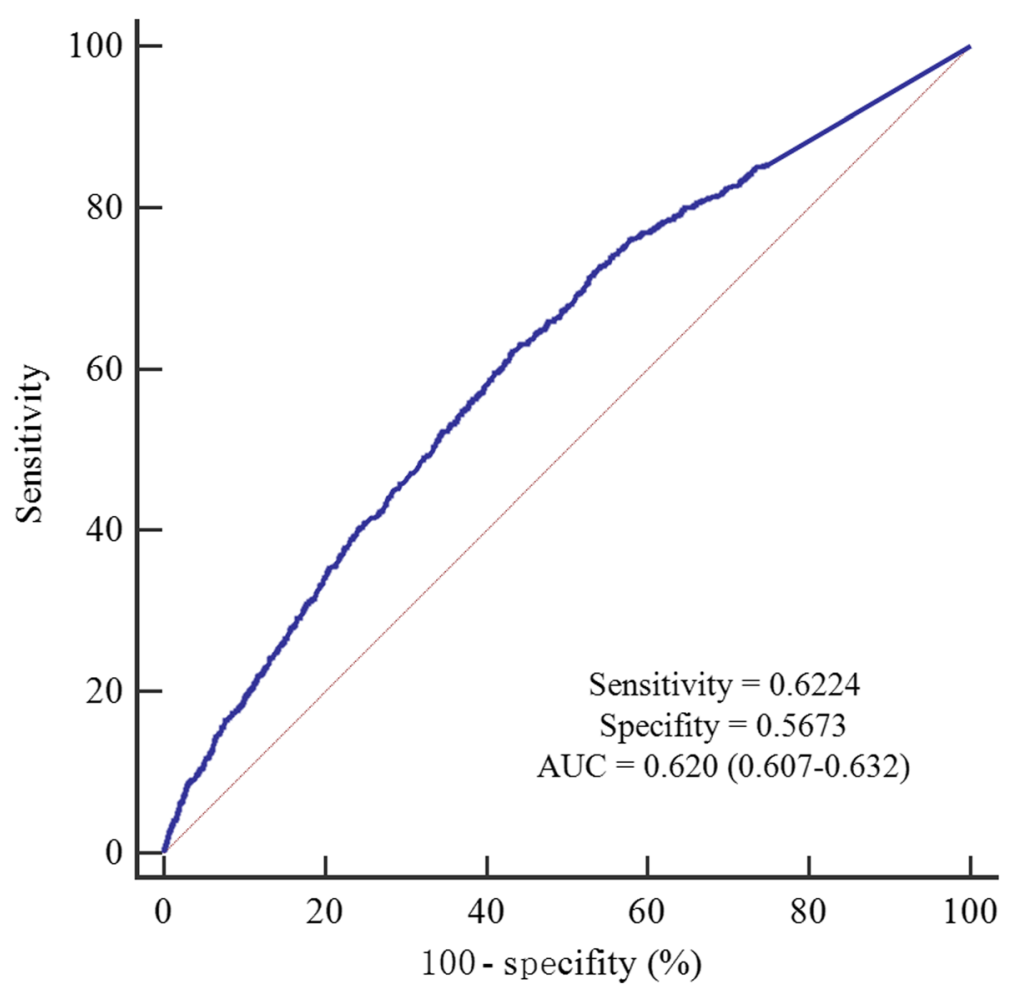

Fig. 2 Receiver operation characteristic (ROC) curve analysis for identifying the cut-off value of pre-treatment Epstein-Barr virus DNA

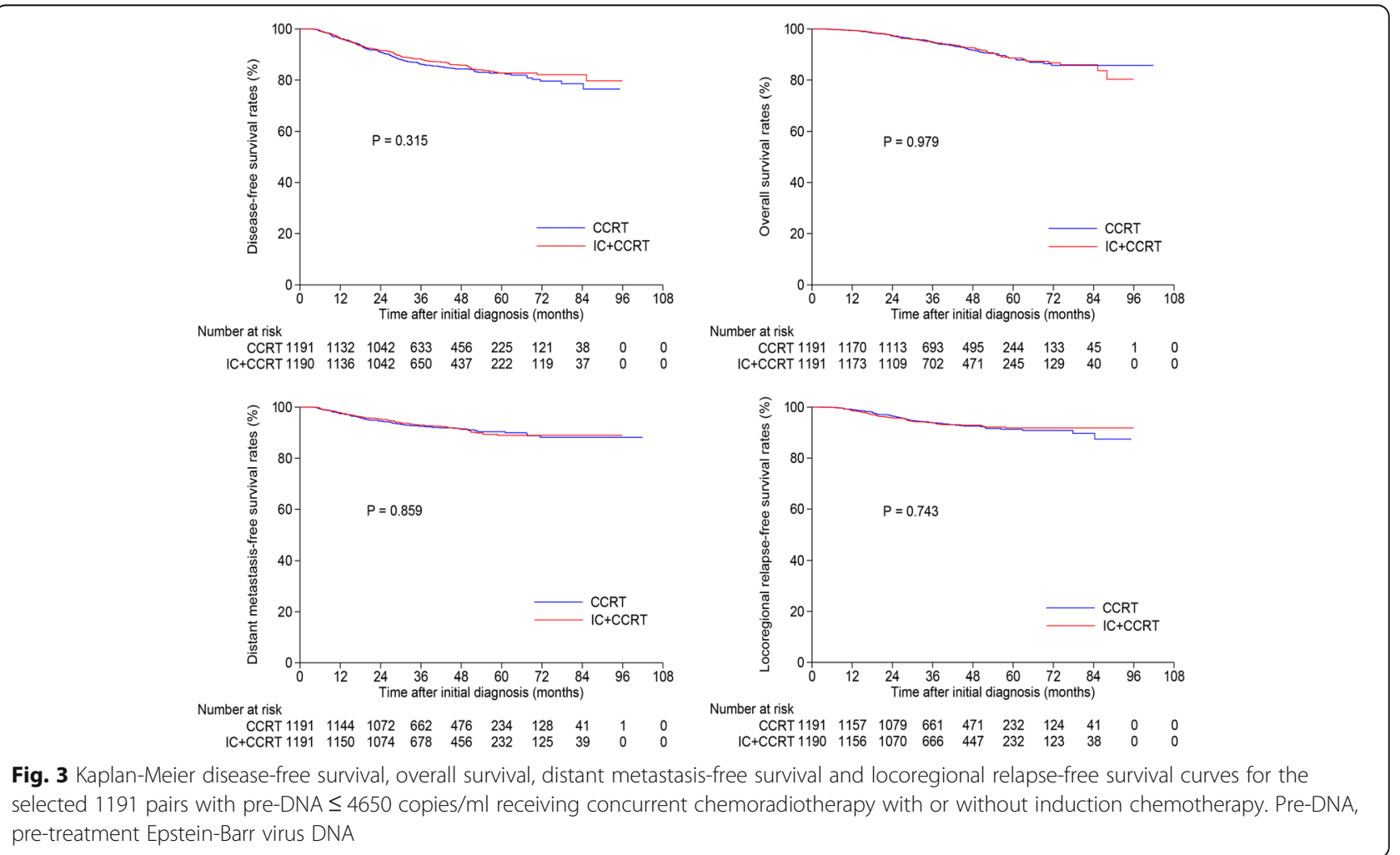




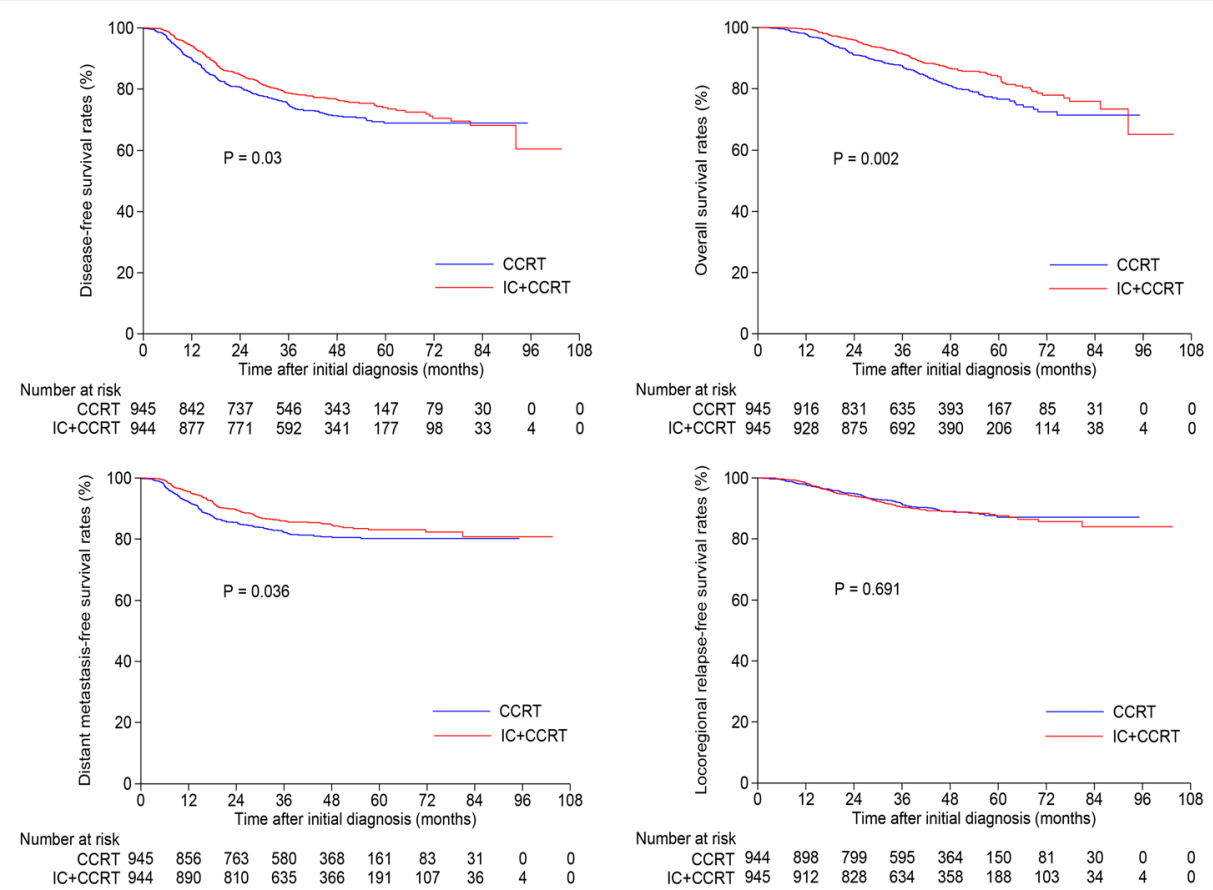

Fig. 4 Kaplan-Meier disease-free survival, overall survival, distant metastasis-free survival and locoregional relapse-free survival curves for the selected 945 pairs with pre-DNA > 4650 copies/ml receiving concurrent chemoradiotherapy with or without induction chemotherapy. Pre-DNA, pre-treatment Epstein-Barr virus DNA

T3-4 N0-1 [10, 11], further revealing that great heterogeneity exists in patients with LA-NPC. Therefore, effective factors should be identified to subdivide patients with different risk groups and then deliver IC. Our study proved pre-DNA could act as that factor.

It is well known that NPC is an EBV-driven malignancy [30, 31]. Our study selected pre-DNA as the only indicator for IC because the prognostic role of EBV DNA in NPC has been proven by numerous studies [13, 32-34]. Possibly, EBV DNA has been the strongest and most widely used factor in NPC so far. Although many other prognostic factors like LDH $[35,36]$ and tumor volume [37] have also been proven effective, they were not been widely proven and evidence supporting them were not too much. We therefore only selected pre-DNA as the indicator. Notably, the cut-off value of pre-DNA in our study was different from that used in other studies $[17,38]$ because we calculate it based on our data. The cut-off value of 4000 copies $/ \mathrm{ml}$ used in the two studies [17, 38] came from other literatures and was not calculated based on their own data. Thus, our results may be more credible and reflect intrinsic relationship of pre-DNA and IC. However, it should be pointed out that common calibrators and PCR master mix should be warranted to reduce variability in plasma EBV DNA numbers [39] before our cut-off value could be applied widely and uniformly.
Among the original cohort without stratification by pre-DNA, no significant survival difference between IC + CCRT and CCRT groups was observed. One possible explanation may be that some patients with low-risk could not benefit from IC and they counteract the benefit for high-risk patients, resulting in non-significant difference. When stratified analysis according to pre-DNA was performed, a different scenario happened. Among patients with low-DNA, IC + CCRT and CCRT achieved comparable survival outcomes; while for those with high-DNA, IC + CCRT group achieved significantly better DFS, OS and DMFS than CCRT group. These results were consistent with previous studies [17, 18, 38]. Undoubtedly, patients with high-DNA had higher tumor burden and risk of distant metastasis, therefore could benefit from IC. Our findings together with previous studies $[17,18,38]$ further supported that pre-DNA could act as a strong and reliable indicator for IC.

Compared with previous studies [17, 18, 38], our study mainly had two advantages. First, all the patients received standard treatment (i.e., CCRT-based regimen was delivered to all patients), thus reducing treatment-related bias. Second, the sample size is large, therefore achieving more powerfully statistical results. By applying PSM and multivariate analysis, we addressed the potential limitations of divergent 
Table 3 Results of multivariate analysis for the selected 945 pairs with pre-treatment Epstein-Barr virus DNA > 4650 copies/ml

\begin{tabular}{|c|c|c|c|}
\hline Endpoints & Variable & $\mathrm{HR}(95 \% \mathrm{Cl})$ & $P$ value $^{a}$ \\
\hline \multirow[t]{6}{*}{ DFS } & Gender, female vs. male & $0.694(0.559-0.862)$ & 0.001 \\
\hline & Family history of cancer, yes vs. no & $1.273(1.042-1.555)$ & 0.018 \\
\hline & $\mathrm{LDH}_{;}>245$ vs. $\leq 245 \mathrm{U} / \mathrm{L}$ & $1.345(1.050-1.723)$ & 0.019 \\
\hline & N category, N2-3 vs. N0-1 & $1.693(1.405-2.039)$ & $<0.001$ \\
\hline & Overall stage, IVA vs. III & $1.349(1.125-1.617)$ & 0.001 \\
\hline & Treatment, IC + CCRT vs. CCRT & $0.817(0.683-0.977)$ & 0.027 \\
\hline \multirow[t]{6}{*}{ OS } & Gender, female vs. male & $0.630(0.472-0.841)$ & 0.002 \\
\hline & Age, $>44$ vs. $\leq 44 y$ & $1.499(1.188-1.892)$ & 0.001 \\
\hline & $\mathrm{LDH}_{;}>245$ vs. $\leq 245 \mathrm{U} / \mathrm{L}$ & $1.510(1.118-2.039)$ & 0.007 \\
\hline & N category, N2-3 vs. N0-1 & $1.820(1.437-2.305)$ & $<0.001$ \\
\hline & Overall stage, IVA vs. III & $1.396(1.110-1.757)$ & 0.004 \\
\hline & Treatment, IC + CCRT vs. CCRT & $0.675(0.537-0.848)$ & 0.001 \\
\hline \multirow[t]{5}{*}{ DMFS } & Gender, female vs. male & $0.674(0.513-0.886)$ & 0.005 \\
\hline & $\mathrm{LDH} ;>245$ vs. $\leq 245 \mathrm{U} / \mathrm{L}$ & $1.658(1.245-2.209)$ & 0.001 \\
\hline & N category, N2-3 vs. N0-1 & $1.874(1.481-2.372)$ & $<0.001$ \\
\hline & Overall stage, IVA vs. III & $1.377(1.100-1.725)$ & 0.005 \\
\hline & Treatment, IC + CCRT vs. CCRT & $0.782(0.626-0.976)$ & 0.03 \\
\hline \multirow[t]{4}{*}{ LRRFS } & Gender, female vs. male & $0.598(0.416-0.859)$ & 0.005 \\
\hline & Family history of cancer, yes vs. no & $1.533(1.128-2.083)$ & 0.006 \\
\hline & N category; N3 vs. N2 & $1.712(1.274-2.301)$ & $<0.001$ \\
\hline & Treatment, IC + CCRT vs. CCRT & $1.063(0.798-1.415)$ & 0.677 \\
\hline
\end{tabular}

Abbreviations: DFS disease-free survival, OS overall survival, DMFS distant metastasis-free survival, LRRFS locoregional relapse-free survival, HR hazard ratio, $C$ I confidence interval, IC induction chemotherapy, CCRT concurrent chemoradiotherapy, LDH lactate dehydrogenase

${ }^{a}$-values were calculated using an adjusted Cox proportional hazards model with backward elimination and the following variables were included: gender (female vs. male), age (> 44y vs. $\leq 44 \mathrm{y}$ ), smoking (yes vs. no), drinking (yes vs. no), family history of cancer (yes vs. no), LDH (> 245 vs. $\leq 245 \mathrm{U} / \mathrm{L}$ ), $\mathrm{T}$ category (T3-4 vs. T1-2), N category (N2-3 vs. N0-1), overall stage (IVA vs. III) and treatment (IC + CCRT vs. CCRT)

confounders, treatment heterogeneity and selection bias associated with retrospective analysis of observational data [40]. The limitations in this study should also be acknowledged. First, our study is retrospective, meaning potential bias may exist. Moreover, the follow-up duration may not be long enough which would produce few events and prevent data from reach statistically significant. Therefore, a longer follow-up length is necessary to further evaluate the role of pre-DNA for IC. Finally, completion of concurrent chemotherapy between IC + CCRT and CCRT groups was not addressed in our study. As shown by previous study, IC could affect the completion of tri-weekly cisplatin regimen $\left(100 \mathrm{mg} / \mathrm{m}^{2}\right)$ [28]. However, the concurrent regimen used in our study was different from that. Therefore, this issue should be addressed in future study.

\section{Conclusion}

In summary, our study revealed that patients with high pre-DNA could benefit from additional IC to
CCRT while those with low pre-DNA could not in LA-NPC in the era of IMRT, indicating pre-DNA may be a feasible and powerful consideration for individualized IC apart from other baseline clinical characteristics. Future randomized clinical trials are warranted to validate our findings.

\section{Additional files}

Additional file 1: Table S1.Baseline characteristics of 6218 patients with locoregionally advanced nasopharyngeal carcinoma. (DOCX 16 kb)

Additional file 2: Figure S1.Kaplan-Meier disease-free survival, overall survival, distant metastasis-free survival and locoregional relapse-free survival curves stratified as pre-DNA $\leq 4650$ or $>4650$ copies/ml for patients with stage III nasopharyngeal carcinoma. Pre-DNA, pre-treatment Epstein-Barr virus DNA. (TIF $417 \mathrm{~kb}$ )

Additional file 3: Figure S2.Kaplan-Meier disease-free survival, overall survival, distant metastasis-free survival and locoregional relapse-free survival curves stratified as pre-DNA $\leq 4650$ or $>4650$ copies $/ \mathrm{ml}$ for patients with stage IVA nasopharyngeal carcinoma. Pre-DNA, pre-treatment Epstein-Barr virus DNA. (TIF $426 \mathrm{~kb}$ )

Additional file 4: Table S2.Baseline characteristics of 3292 patients with pre-treatment Epstein-Barr virus DNA $\leq 4650$ copies/ml. (DOCX 16 kb) 
Additional file 5: Table S3.Baseline characteristics of selected 1191 pairs with pre-treatment Epstein-Barr virus DNA $\leq 4650$ copies $/ \mathrm{ml}$. (DOCX $16 \mathrm{~kb}$ )

Additional file 6: Table S4.Results of multivariate analysis for the selected 1191 pairs with pre-treatment Epstein-Barr virus DNA $\leq 4650$ copies/ml. (DOCX $15 \mathrm{~kb})$

Additional file 7: Table S5.Baseline characteristics of 2926 patients with pre-treatment Epstein-Barr virus DNA > 4650 copies/ml. (DOCX 16 kb)

Additional file 8: Table S6.Baseline characteristics of selected 945 pairs with pre-treatment Epstein-Barr virus DNA > 4650 copies/ml. (DOCX 16 kb)

\section{Abbreviations}

CCRT: Concurrent chemoradiotherapy; Cl: Confidence intervals; DFS: Diseasefree survival; DMFS: Distant metastasis-free survival; EBV: Epstein-Barr virus; HR: Hazard ratios; IC: Induction chemotherapy; IMRT: Intensity-modulated radiotherapy; LA-NPC: Locoregionally advanced nasopharyngeal carcinoma; LDH: Lactate dehydrogenase; LRRFS: Locoregional relapse-free survival; MRI: Magnetic resonance imaging; NPC: Asopharyngeal carcinoma; OS: Overall survival; PCR: Polymerase chain reaction; PET: Positron emission tomography; PF: 5-fluorouracil with cisplatin; Pre-DNA: Pre-treatment Epstein-Barr virus; ROC: Receiver operation characteristic; RT: Radiation therapy; TP: Docetaxel with cisplatin; TPF: Docetaxel with 5-fluorouracil and cisplatin; UICC/AJCC: International Union against Cancer/American Joint Committee on Cancer; WHO: World Health Organization

\section{Acknowledgements}

We sincerely thank Dr. Wei Liang and Dr. Lei Shi (Yidu Cloud Technology Ltd., Beijing, China) for providing technical support in extracting study data from their big-data intelligence database platform.

\section{Funding}

This work received grants. Study design and data collection: National Science \& Technology Pillar Program during the Twelfth Five-year Plan Period (2014BAI09B10) and Natural Science Foundation of Guangdong Province (2017A030312003). Data analysis and interpretation: National Natural Science Foundation of China (81572658) and Program of Introducing Talents of Discipline to Universities (B14035). Manuscript writing and revision: Innovation Team Development Plan of the Ministry of Education (No. IRT_17R110) and Guangzhou key medical discipline construction project fund.

\section{Availability of data and materials}

The datasets generated and analyzed during the current study are deposited in the Research Data Deposit (RDDA2017000416, http://www.researchdata.org.cn/), and available from the corresponding author for purpose of scientific research.

\section{Authors' contributions}

$J Z, H P$ and JM contributed to study design and conception. JZ, HP, LZL, LT, YZ and WFL contributed to data acquisition. JZ, HP and AHL analyzed and interpreted the data. HP, WFL, LZL, LT and YZ contributed to manuscript revision. WFL, LZL, LT and YS contributed to quality control and review of the data and manuscript. All authors have read and approved the final version of the submitted manuscript.

\section{Ethics approval and consent to participate}

Written Informed consent was obtained from all patients before treatment and this study was approved by the institutional research ethics committee of Sun Yat-sen University Cancer Center.

\section{Consent for publication}

Not applicable.

\section{Competing interests}

The authors declare that they have no competing interests.

\section{Publisher's Note}

Springer Nature remains neutral with regard to jurisdictional claims in published maps and institutional affiliations.

\section{Author details}

'Department of Radiation Oncology, Affiliated Cancer Hospital \& Institute of Guangzhou Medical University, Guangzhou 510000, People's Republic of China. ${ }^{2}$ Department of Radiation Oncology, Sun Yat-sen University Cancer Center, State Key Laboratory of Oncology in Southern China, Collaborative Innovation Center for Cancer Medicine, Guangdong Key Laboratory of Nasopharyngeal Carcinoma Diagnosis and Therapy, Guangzhou 510060, People's Republic of China. ${ }^{3}$ Imaging Diagnosis and Interventional Center, Sun Yat-sen University Cancer Center, State Key Laboratory of Oncology in Southern China, Collaborative Innovation Center for Cancer Medicine, Guangzhou, People's Republic of China. ${ }^{4}$ Department of Medical Statistics and Epidemiology, School of Public Health, Sun Yat-sen University, Guangzhou, People's Republic of China. ${ }^{5}$ State Key Laboratory of Oncology in South China, Department of Radiation Oncology, Sun Yat-sen University Cancer Center, 651 Dongfeng Road East, Guangzhou 510060, People's Republic of China.

Received: 16 April 2018 Accepted: 4 December 2018

Published online: 19 December 2018

\section{References}

1. Torre LA, Bray F, Siegel RL, et al. Global cancer statistics, 2012. CA Cancer J Clin. 2015;65:87-108

2. Wei KR, Zheng RS, Zhang SW, et al. Nasopharyngeal carcinoma incidence and mortality in China, 2013. Chin J Cancer. 2017;36:90.

3. Al-Sarraf M, LeBlanc M, Giri PG, et al. Chemoradiotherapy versus radiotherapy in patients with advanced nasopharyngeal cancer: phase III randomized intergroup study 0099. J Clin Oncol. 1998;16:1310-7.

4. Lin JC, Jan JS, Hsu CY, et al. Phase III study of concurrent chemoradiotherapy versus radiotherapy alone for advanced nasopharyngeal carcinoma: positive effect on overall and progression-free survival. J Clin Oncol. 2003;21:631-7.

5. Yi JL, Gao L, Huang XD, et al. Nasopharyngeal carcinoma treated by radical radiotherapy alone: ten-year experience of a single institution. Int J Radiat Oncol Biol Phys. 2006;65:161-8.

6. Lai SZ, Li WF, Chen L, et al. How does intensity-modulated radiotherapy versus conventional two-dimensional radiotherapy influence the treatment results in nasopharyngeal carcinoma patients? Int J Radiat Oncol Biol Phys. 2011;80:661-8.

7. Hong RL, Ting LL, Ko JY, et al. Induction chemotherapy with mitomycin, epirubicin, cisplatin, fluorouracil, and leucovorin followed by radiotherapy in the treatment of locoregionally advanced nasopharyngeal carcinoma. J Clin Oncol. 2001;19:4305-13.

8. Hui EP, Ma BB, Leung SF, et al. Randomized phase II trial of concurrent cisplatin-radiotherapy with or without neoadjuvant docetaxel and cisplatin in advanced nasopharyngeal carcinoma. J Clin Oncol. 2009;27:242-9.

9. Airoldi M, Gabriele P, Gabriele AM, et al. Induction chemotherapy with carboplatin and taxol followed by radiotherapy and concurrent weekly carboplatin + taxol in locally advanced nasopharyngeal carcinoma. Cancer Chemoth Pharm. 2011;67:1027-34.

10. Lan XW, Xiao Y, Zou XB, et al. Outcomes of adding induction chemotherapy to concurrent chemoradiotherapy for stage T3N0-1 nasopharyngeal carcinoma: a propensity-matched study. Onco Targets Ther. 2017;10:3853-60.

11. Wu LR, Yu HL, Jiang N, et al. Prognostic value of chemotherapy in addition to concurrent chemoradiotherapy in T3-4N0-1 nasopharyngeal carcinoma: a propensity score matching study. Oncotarget. 2017;8:76807-15.

12. Tang LQ, Li CF, Li J, et al. Establishment and validation of prognostic nomograms for endemic nasopharyngeal carcinoma. J Natl Cancer Inst. 2016;108.

13. Lin JC, Wang WY, Chen KY, et al. Quantification of plasma Epstein-Barr virus DNA in patients with advanced nasopharyngeal carcinoma. N Engl J Med. 2004;350:2461-70.

14. Hou X, Zhao C, Guo Y, et al. Different clinical significance of pre- and posttreatment plasma Epstein-Barr virus DNA load in nasopharyngeal carcinoma treated with radiotherapy. Clin Oncol. 2011;23:128-33.

15. Leung SF, Chan KC, Ma BB, et al. Plasma Epstein-Barr viral DNA load at midpoint of radiotherapy course predicts outcome in advanced-stage nasopharyngeal carcinoma. Ann Oncol. 2014;25:1204-8.

16. Twu CW, Wang WY, Chen CC, et al. Metronomic adjuvant chemotherapy improves treatment outcome in nasopharyngeal carcinoma patients with 
postradiation persistently detectable plasma Epstein-Barr virus deoxyribonucleic acid. Int J Radiat Oncol Biol Phys. 2014;89:21-9.

17. Guo SS, Tang LQ, Chen QY, et al. Induction chemotherapy followed by concurrent chemoradiotherapy versus concurrent chemoradiotherapy alone in stage III-IVb nasopharyngeal carcinoma patients with Epstein-Barr virus DNA >/=4000 copies/ml: a matched study. Oncotarget. 2016;7:29739-48.

18. Peng $H$, Chen L, Li WF, et al. Prognostic value of neoadjuvant chemotherapy in Locoregionally advanced nasopharyngeal carcinoma with low pre-treatment Epstein-Barr virus DNA: a propensity-matched analysis. J Cancer. 2016;7:1465-71.

19. Lv JW, Chen YP, Huang XD, et al. Hepatitis B virus screening and reactivation and management of patients with nasopharyngeal carcinoma: a large-scale, big-data intelligence platform-based analysis from an endemic area. Cancer. 2017;123:3540-9.

20. Shao JY, Zhang Y, Li YH, et al. Comparison of Epstein-Barr virus DNA level in plasma, peripheral blood cell and tumor tissue in nasopharyngeal carcinoma. Anticancer Res. 2004;24:4059-66.

21. Chen YP, Sun $Y$, Chen $L$, et al. Surrogate endpoints for overall survival in combined chemotherapy and radiotherapy trials in nasopharyngeal carcinoma: meta-analysis of randomised controlled trials. Radiother Oncol. 2015;116:157-66.

22. Rotolo F, Pignon JP, Bourhis J, et al. Surrogate end points for overall survival in loco-regionally advanced nasopharyngeal carcinoma: an individual patient data meta-analysis. J Natl Cancer Inst. 2017;109.

23. Sun X, Su S, Chen C, et al. Long-term outcomes of intensity-modulated radiotherapy for 868 patients with nasopharyngeal carcinoma: an analysis of survival and treatment toxicities. Radiother Oncol. 2014;110:398-403.

24. Kam MK, Teo PM, Chau RM, et al. Treatment of nasopharyngeal carcinoma with intensity-modulated radiotherapy: the Hong Kong experience. Int J Radiat Oncol Biol Phys. 2004;60:1440-50.

25. Baujat B, Audry H, Bourhis J, et al. Chemotherapy in locally advanced nasopharyngeal carcinoma: an individual patient data meta-analysis of eight randomized trials and 1753 patients. Int J Radiat Oncol Biol Phys. 2006;64:47-56.

26. Chen L, Hu CS, Chen XZ, et al. Adjuvant chemotherapy in patients with locoregionally advanced nasopharyngeal carcinoma: long-term results of a phase 3 multicentre randomised controlled trial. Eur J Cancer. 2017;75:150-8.

27. Frikha $M$, Auperin $A$, Tao $Y$, et al. A randomized trial of induction docetaxel-cisplatin-5FU followed by concomitant cisplatin-RT versus concomitant cisplatin-RT in nasopharyngeal carcinoma (GORTEC 2006-02). Ann Oncol. 2018;29:731-6.

28. Sun Y, Li WF, Chen NY, et al. Induction chemotherapy plus concurrent chemoradiotherapy versus concurrent chemoradiotherapy alone in locoregionally advanced nasopharyngeal carcinoma: a phase 3, multicentre, randomised controlled trial. Lancet Oncol. 2016;17:1509-20.

29. Tan T, Lim WT, Fong KW, et al. Concurrent chemo-radiation with or without induction gemcitabine, carboplatin, and paclitaxel: a randomized, phase 2/3 trial in locally advanced nasopharyngeal carcinoma. Int J Radiat Oncol Biol Phys. 2015;91:952-60.

30. Young LS, Rickinson AB. Epstein-Barr virus: 40 years on. Nat Rev Cancer. 2004:4:757-68

31. Chen CJ, Hsu WL, Yang HI, et al. Epidemiology of virus infection and human cancer. Recent Results Cancer Res. 2014;193:11-32.

32. Chan AT, Lo YM, Zee B, et al. Plasma Epstein-Barr virus DNA and residual disease after radiotherapy for undifferentiated nasopharyngeal carcinoma. J Natl Cancer Inst. 2002;94:1614-9.

33. Lo YM, Chan LY, Chan AT, et al. Quantitative and temporal correlation between circulating cell-free Epstein-Barr virus DNA and tumor recurrence in nasopharyngeal carcinoma. Cancer Res. 1999;59:5452-5.

34. Peng $H$, Guo R, Chen L, et al. Prognostic impact of plasma Epstein-Barr virus DNA in patients with nasopharyngeal carcinoma treated using intensitymodulated radiation therapy. Sci Rep. 2016;6:22000.

35. Wan XB, Wei L, Li H, et al. High pretreatment serum lactate dehydrogenase level correlates with disease relapse and predicts an inferior outcome in locally advanced nasopharyngeal carcinoma. Eur J Cancer. 2013:49:2356-64.

36. Zhou GQ, Tang LL, Mao YP, et al. Baseline serum lactate dehydrogenase levels for patients treated with intensity-modulated radiotherapy for nasopharyngeal carcinoma: a predictor of poor prognosis and subsequent liver metastasis. Int J Radiat Oncol Biol Phys. 2012;82:e359-65.
37. Guo $R$, Sun $Y, Y u X L$, et al. Is primary tumor volume still a prognostic factor in intensity modulated radiation therapy for nasopharyngeal carcinoma? Radiother Oncol. 2012;104:294-9.

38. Du XJ, Tang LL, Mao YP, et al. Circulating EBV DNA, globulin and nodal size predict distant metastasis after intensity-modulated radiotherapy in stage II nasopharyngeal carcinoma. J Cancer. 2016;7:664-70.

39. Le QT, Zhang Q, Cao H, et al. An international collaboration to harmonize the quantitative plasma Epstein-Barr virus DNA assay for future biomarker-guided trials in nasopharyngeal carcinoma. Clin Cancer Res. 2013;19:2208-15.

40. Austin PC. The relative ability of different propensity score methods to balance measured covariates between treated and untreated subjects in observational studies. Med Decis Mak. 2009;29:661-77.
Ready to submit your research? Choose BMC and benefit from:

- fast, convenient online submission

- thorough peer review by experienced researchers in your field

- rapid publication on acceptance

- support for research data, including large and complex data types

- gold Open Access which fosters wider collaboration and increased citations

- maximum visibility for your research: over $100 \mathrm{M}$ website views per year

At BMC, research is always in progress.

Learn more biomedcentral.com/submissions 